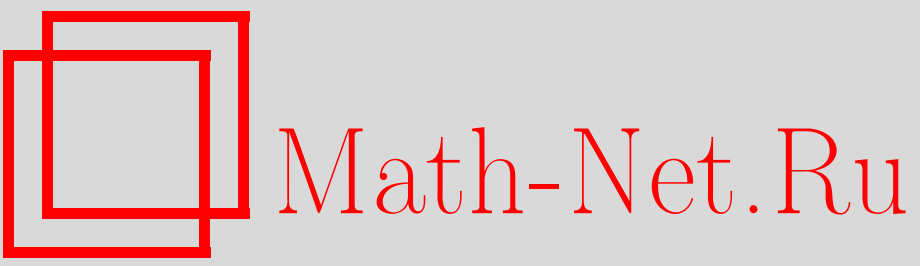

А. Д. Васильев, Механизм диффузионного массопереноса под действием микросекундных механических импульсов в крупнокристаллической эпитаксиальной системе $\mathrm{Pd} / \mathrm{Ag}$, Вестн. Сам. гос. техн. ун-та. Сер. Физ.-мат. науки, 2010, выпуск 1(), 253-257

DOI: https://doi.org/10.14498/vsgtu699

Использование Общероссийского математического портала Math-Net.Ru подразумевает, что вы прочитали и согласны с пользовательским соглашением http://www.mathnet.ru/rus/agreement

Параметры загрузки:

IP: 35.173 .219 .149

26 апреля 2023 г., 08:41:58 
УДК 539.219.3

\title{
МЕХАНИЗМ ДИФФУЗИОННОГО МАССОПЕРЕНОСА ПОД ДЕЙСТВИЕМ МИКРОСЕКУНДНЫХ МЕХАНИЧЕСКИХ ИМПУЛЬСОВ В КРУПНОКРИСТАЛЛИЧЕСКОЙ ЭПИТАКСИАЛЬНОЙ СИСТЕМЕ Pd/Ag
}

\author{
А. Д. Василъев \\ Самарский государственный технический университет, \\ 443100, Самара, ул. Молодогвардейская, 244. \\ E-mail: vasilyevad@mail.ru
}

Предложен механизм диффузионного массопереноса под действием микросекундных механических импульсов. Результаты эксперимента можно объяснить, описывая механические импульсы как совокупность фононов.

Ключевые слова: дифбузионный массоперенос, фононы.

Введение. При импульсном механическом деформировании наблюдается ускоренный массоперенос в металлах и сплавах [1]. Однако в настоящее время нет общепризнанного механизма такого массопереноса. Практически во всех работах полагается, что массоперенос происходит за счёт увлечения межузельных атомов фронтом ударной волны; иногда считается, что к этому механизму добавляется увлечение атомов движущимися дислокациями [2]. Основное затруднение возникает при попытке предложить механизм возникновения межузельных атомов, энергия образования которых велика. Есть результаты, свидетельствующие о том, что границы зерен в высокодисперсных структурах (а именно такие структуры часто формируются при импульсных воздействиях) обладают повышенной диффузионной проницаемостью [3]. В работе [4] изучался массоперенос под действием микросекундных механических импульсов в условиях, когда отсутствует активная пластическая деформация, что существенно облегчает анализ возможных механизмов диффузии. В настоящей работе проведено дальнейшее исследование механизма диффузионного массопереноса под действием микросекундных механических импульсов на примере крупнокристаллической эпитаксиальной системы $\mathrm{Pd} / \mathrm{Ag}$.

Методика эксперимента. Образцы готовились напылением палладия в вакууме на серебряную подложку, имеющую средний размер зёрен 30-40 мкм и плотность дислокаций $4 \cdot 10^{13} \mathrm{~m}^{-2}$. Размер готовых образцов - $30 \times 5 \times 2 \mathrm{мм}$; толщина палладиевой плёнки - 1 мкм. Микросекундные механические импульсы генерировались с помощью искрового разряда. При разряде батареи конденсаторов между исследуемым образцом (рис. 1, цифры 3 и 4) и вспомогательным электродом (рис. 1, цифра 5) возникала электрическая искра, под действием которой происходило испарение части образца, в результате чего в образце возникали импульсы сжатия. Величина давления в палладиевой плёнке во время искрового разряда измерялась пьезоэлектрическим поливинилхлоридным датчиком. За время одного разряда конденсаторов в образце возникал не один длительный механический импульс, а серия из 300 коротких импульсов. Длительность одного короткого импульса - около 1 мкс, интервал между двумя импульсами в серии -2 мкс.

Плотность дислокаций в образцах определялась по уширению рентгеновских дифракционных линий (111) и (222). Величина эффективного коэффициента массопереноса находилась с помощью анализа профиля рентгеновской дифракционной линии (111) твёрдого раствора в диффузионной зоне образца. Әффективный ко-

Алексей Дмитриевич Васильев (д.ф.-м.н.), профессор, каф. общей физики и физики нефтегазового производства. 


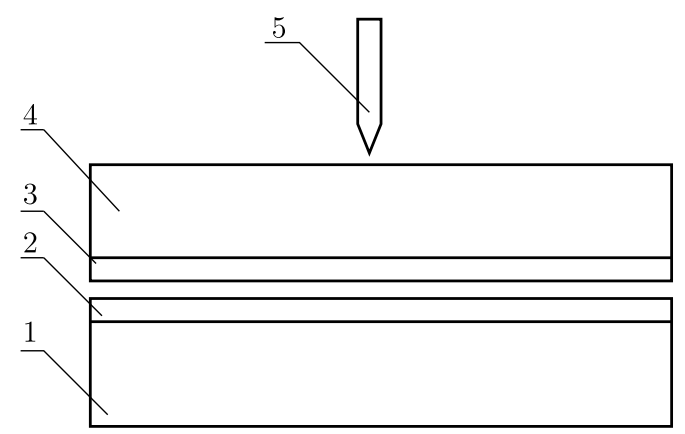

Рис. 1. Схема эксперимента по исследованию диффузионного массопереноса под действием коротких механических импульсов: 1 и 2 - откольный образец (образец № 1 ), состоящий из серебряной подложки (1) и палладиевой плёнки (2); 3 и 4 - исследуемый образец (образец № 2), состоящий из серебряной подложки (4) и палладиевой плёнки (3); 5 - вспомогательный электрод

эффициент массопереноса определялся в палладиевой плёнке в области содержания 90-95\% Pd.

Результаты эксперимента и их обсуждение. Значения коэффициента массопереноса (рис. 2), полученные в работе [4], найдены в эксперименте, схема которого приведена на рис. 1. Механический импульс возникал на верхней поверхности образца, помеченного цифрами 3 и 4, и проходил сквозь палладиевую пленку (цифра 3). Форма этого импульса, снятая с помощью пьезодатчика при тактовой частоте запоминающей электронной схемы 10 МГц, представлена на рис. 3, а. Давление у импульсов одной серии было различным, средняя величина давления находилась в интервале 0,4-0,8 ГПа. Но в отдельных сериях наблюдались единичные импульсы до 1,5 ГПа.

Для дальнейшего исследования диффузионного массопереноса под действием коротких механических импульсов можно провести эксперимент, в котором на палладиевую пленку одновременно действуют два примерно одинаковых по абсолютной величине, но противоположных по направлению движения и знаку механических импульса.

В схеме эксперимента, изображенного на рис. 1, импульс, возникнув на верхней поверхности образца № 2 (цифра 3 и 4), пройдёт через оба образца, отразится от нижней поверхности образца № 1 (цифры 1 и 2) и пойдёт в противоположную сторону. При отражении волны сжатия от свободной поверхности, то есть от границы,

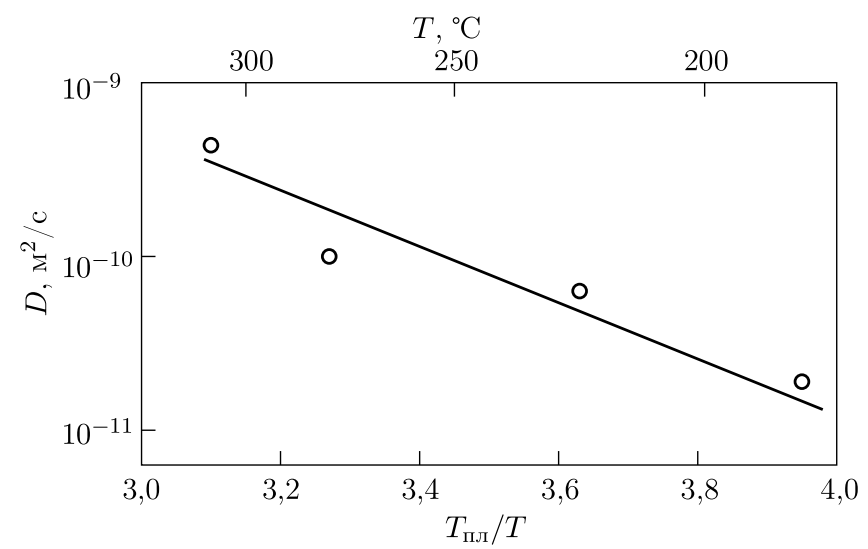

Рис. 2. Значения коэффициента диффузионного массопереноса $D$ серебра в области содержания 90-95\% $\mathrm{Pd}$ под действием коротких механических импульсов в системе $\mathrm{Pd} / \mathrm{Ag}$ 


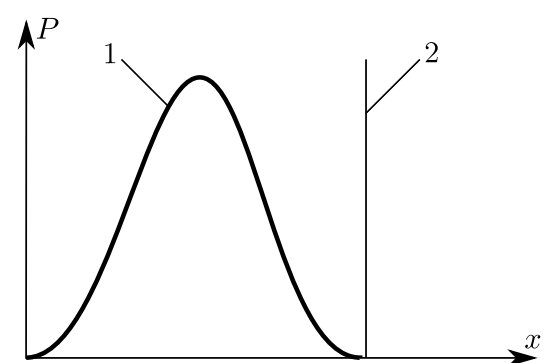

a

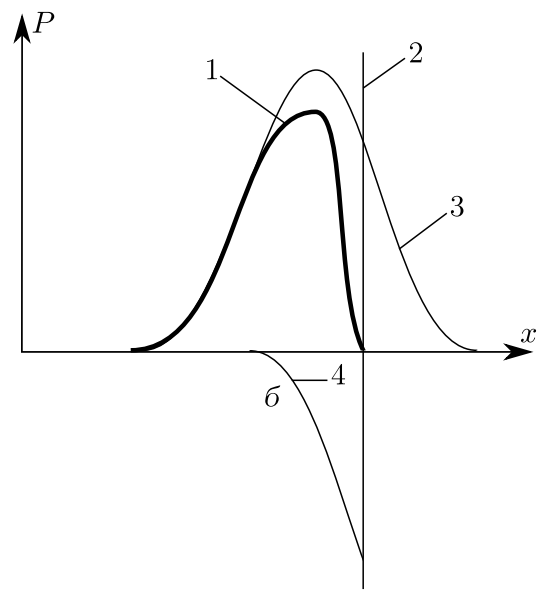

Рис. 3. Изменение распределение давления механического импульса (а) в образце при отражении импульса от тыльной поверхности образца (б): 1 - суммарный импульс, 2 - тыльная сторона образца, 3 - исходный импульс, 4 - часть отражённого импульса

на которой плотность материала падает, будет формироваться волна растяжения, движущаяся в направлении, противоположном волне сжатия. В рассматриваемом случае давление в импульсе не очень высокое: максимум 1,5 ГПа, поэтому скорость импульса равна скорости звука в серебре и примерно равна $2640 \mathrm{~m} / \mathrm{c}$. При такой скорости длина импульса будет примерно 2,5 мм, то есть чуть больше толщины образца, которая равна 2 мм. При таких условиях сначала через палладиевую пленку проходит импульс сжатия, а отражённый импульс растяжения - примерно через 1 мкс после прохождения импульса сжатия. Прямой импульс от верхней поверхности образца № 2, где он возникает, до палладиевой плёнки обоих образцов проходит расстояние, равное толщине образца, а отражённый импульс проходит до палладиевых пленок обоих образцов расстояние в три раза большее, что приводит к его сильному ослаблению и, как показывает эксперимент, не влияет на диффузионные процессы в образцах. Поэтому в экспериментах, проведённых по схеме, изображенной на рис. 1, можно учитывать только один прямой импульс, движущийся сверху вниз. Если удалить нижний (откольный) образец, то импульс будет отражаться от нижней поверхности теперь уже единственного образца, то есть прямой импульс сжатия и отражённый импульс растяжения будут проходить через межфазную границу и палладиевую пленку в одно и то же время. Эта ситуация, когда межфазная граница и палладиевая плёнка окажутся одновременно под действием импульсов противоположных направлений с амплитудами, одинаковыми по абсолютной величине и разными по знаку, отображена на рис. 3.

Из рис. 3 видно, что появление отраженного импульса приводит к уменьшению амплитуды суммарного импульса в палладиевой плёнке и практической остановке этого результирующего импульса. Фронт импульса практически не перемещается. Примерная величина импульса сжатия в палладиевой пленке определяется отношением $h / L$, где $h$ - толщина плёнки палладия, $L$ - длина фронта импульса. В рассматриваемом случае $h=1 \mathrm{мкм}, L=1 \mathrm{мм}$, то есть величина давления в палладиевой плёнке составляет $0,1 \%$ от максимального значения давления сжатия в механическом импульсе.

Из всего изложенного можно сделать вывод о том, что удаление образца № 1 (рис. 1) приводит к уменьшению давления в палладиевой плёнке в 1000 раз, более того - фронт короткого механического импульса становится практически неподвижным и увлекать точечные дефекты уже никак не может. Однако эксперимент показывает, что изменение параметров импульса не приводит к существенному изменению характеристик диффузионного массопереноса. Значения эффективного коэффициента массопереноса $D$ остаются такими, как показано на рис. 2 . 
Объяснить полученные результаты можно, если рассматривать короткие механические импульсы как поток когерентных фононов. В этом случае отражение волны от поверхности образца означает, что наряду с потоком фононов, движущихся в прямом направлении (от подложки к плёнке), появляется поток фононов, движущихся в обратном направлении (от плёнки к подложке). Появление второго потока фононов не приводит к существенному ослаблению плотности потока фононов, движущихся в прямом направлении, или к уменьшению их скорости, тем более к их остановке, подобно остановке фронта механического импульса при отражении этого импульса от поверхности образца.

В рассматриваемом случае ситуация ещё проще. Поток фононов, образующих отражённую волну и движущихся в направлении от плёнки к подложке, создаёт поле растягивающих напряжений, поэтому импульсы таких фононов направлены в сторону, противоположную направлению их движения, т. е. оба потока фононов будут приводить к массопереносу в одном направлении: от подложки к плёнке. Появление отражённой волны должно приводить к увеличению эффективного коэффициента массопереноса, но на какую величину, определить довольно сложно, т. к. необходимо хорошо знать детали процесса взаимодействия фононов и точечных дефектов. В настоящее время теория такого процесса не разработана, делаются лишь первые попытки теоретически учитывать взаимодействие между фононами и точечными дефектами в процессе диффузии [5]. Эксперимент же показывает, что появление отражённого импульса в пределах ошибки эксперимента, которая вряд ли превышает $50 \%$, не приводит к изменению эффективного коэффициента массопереноса. Поэтому можно сделать вывод о том, что основную роль в диффузионном массопереносе в рассматриваемом случае играет поток фононов, движущихся по направлению от подложки к плёнке.

Так как фононы кроме корпускулярных обладают и волновыми свойствами, то на их поведении должны сказываться поверхностные эффекты. Поэтому рассуждения о влиянии поверхности образца на параметры механического импульса, приведённые выше, справедливы и для фононов. Решающим фактором в рассматриваемом случае является соотношение длины волны фонона и толщины плёнки. Длина волны фонона с энергией ниже энергии тепловых колебаний решётки при комнатной температуре может быть равна нескольким межатомным расстояниям, что на три порядка меньше величины толщины плёнки. Поэтому удаление откольного образца (рис. 1) не должно приводить к существенному изменению параметров массопереноса, что и наблюдается экспериментально.

Если в образце понизить плотность дислокаций до величины менее $10^{8} \mathrm{M}^{-2}$, то массоперенос не наблюдается. Это говорит о том, что дислокации в рассматриваемых процессах играют важную роль. С учётом последнего обстоятельства можно предположить, что возможным механизмом массопереноса является увлечение фононами межузельных атомов, находящихся в ядрах дислокаций. Такие атомы сильно деформируют решетку, поэтому должны сильно взаимодействовать с фононами. Движение таких дефектов происходит не по эстафетному механизму, характерному для межузельных атомов, находящихся в решётке, а за счёт перемещения самого атома примеси, что должно резко повышать коэффициент диффузии.

Таким образом, наиболее вероятным механизмом диффузионного массопереноса под действием микросекундных механических импульсов в условиях, когда отсутствует активная пластическая деформация, является увлечение точечных дефектов фононами, образующими механические импульсы.

\section{БИБЛИОГРАФИЧЕСКИЙ СПИСОК}

1. Лариков Л.Н., Фалъченко В.М., Мазанко В. Ф. Аномальное ускорение диффузии при импульсном нагружении металлов// Докл. АН СССР. Сер. математика и физика, 1975. - Т. 221, № 5. - C. 1073-1075.

2. Бекренев А. Н., Эпштейн Г. Н. Последеформационные процессы высокоскоростного нагружения. - М.: Металлургия, 1992. - 158 с. 
3. Колобов Ю. Р., Валиев Р. З., Грабовеикая Г. П. и др. Зернограничная диффузия и свойства наноструктурных материалов. - Новосибирск: Наука, 2001. - 232 с.

4. Бекренев А.Н., Васильев А. Д. Массоперенос в системе Ag (подложка) - Pd (плёнка) под действием механических импульсов микросекундной длительности // Физика и химия обработки материалов, 1996. - № 4. - С. 64-66.

5. Itskovich I. F., Sorbello R.S. Phonon-assisted diffusion and electromigration of light interstitials in metals // Phys. Rev. B, 1992. - Vol. 45, No. 2. — P. 718-727.

Поступила в редакцию 14/VI/2009;

в окончательном варианте - 13/XI/2009.

MSC: 80A20, 80-05, 74K20

\section{MECHANISM OF DIFFUSION MASS TRANSFER UNDER THE INFLUENCE OF MICROSECONDS MECHANICAL PULSES IN COARS-CRYSTALLINE EPITAXIAL SYSTEM Pd/Ag}

\section{A.D. Vasil'ev}

Samara State Technical University,

244, Molodogvardeyskaya str., Samara, 443100.

E-mail: vasilyevad@mail.ru

Mechanism of diffusion masstransport under influence of microsecond mechanical pulses is presented. The result of the experiment can be explained by describing the mechanical pulses as the sum of phonons.

Key words: diffusion mass transfer, phonons.

Original article submitted 14/VI/2009; revision submitted 13/XI/2009.

Alexey D. Vasil'ev (Dr. Sci. (Phys. \& Math.)), Professor, Dept. of General Physics. 